Check for updates

The BMJ

Cite this as: BMJ 2020;371:m4302 http://dx.doi.org/10.1136/bmj.m4302 Published: 05 November 2020

\section{Covid-19: Care home residents in England should have "safe spaces" for visits from family and friends, says guidance}

\author{
Clare Dyer
}

All care home residents in England should be allowed to receive visits from family and friends in a covid secure way despite new lockdown restrictions coming into force on 5 November, the Department of Health and Social Care will make clear in new guidance.

The latest guidance, which has still to be published, marks a U turn from the department's former policy during the lesser regional restrictions that preceded the new England-wide lockdown. The earlier guidance told thousands of care homes in England that visiting should be stopped in areas with tier 3 lockdown restrictions, apart from in exceptional circumstances such as visiting someone receiving treatment or at the end of life.

Ministers have bowed to pressure from relatives, residents, and operators of care homes in deciding to issue the guidance. The change also follows a memo issued by a High Court judge, Mr Justice Hayden, who is vice president of the Court of Protection, which hears cases involving people who lack the mental capacity to take their own decisions.

He said that the court, which has been facing legal challenges by the relatives of care home residents who were banned from visiting, was concerned about the lockdown's effect on elderly people.

\section{Visiting pods}

The guidance will provide that care homes, many of which have not allowed visits since March, will be encouraged and supported to provide safe visiting opportunities, geared to individual residents and the facilities and layout of the home, using social distancing and personal protective equipment. It will recommend that homes should put in place covid secure opportunities for families to meet, such as floor-to-ceiling screens, visiting pods, and window visits.

The Department for Health and Social Care says that options could include using visiting areas, or pods, where the visitor and resident enter through different entrances and are separated by screens, such that visitors need not enter the care home. Other suggestions are outdoor visits with one other person and further support for virtual visits, to encourage the use of video calls.

Plans are being developed to allow one family member or friend to be designated as a key worker and allowed to visit the care home, supported by regular testing. Trials are set to begin this month.

England's health and social care secretary, Matt Hancock, said, "I know how heart breaking and incredibly frustrating it has been for families and friends who haven't been able to see their loved ones during the pandemic. Care homes should feel empowered by this new guidance to look at safe options to allow visits to care homes that suit their residents and facilities.

"We've seen some really innovative solutions used to help families see each other safely face to face, which has been life changing for some.” 